https://doi.org/10.18778/0208-6107.39.06

\author{
Andrea Oldani \\ (iD) https://orcid.org/0000-0003-0632-1684 \\ Politecnico di Milano \\ Department of Architecture and Urban Studies \\ andrea.oldani@polimi.it
}

\title{
MILAN AND ITS LOST RIVER: WHEN SURVIVING IMAGES REPRESENT UNIQUE NARRATIONS OF INVISIBLE RELATIONSHIPS
}

\begin{abstract}
One of the most predictable implications of photography consists of the ability to fix some images returning them in a variable timeframe for the observation. In all the major world cities, it is common to incur in some book where recent photos are compared to old ones searching the same point of view in order to make the comparison more accurate and stimulate the critical ability of the observer. An exercise that sometimes stimulates a sort of regret for the past, pointing out a diffused excess of nostalgia for times gone by. Nevertheless, the reality and meaning of modern city images are not always so prosaic. What happens when photographs are evocative of a reality that is completely lost in the collective imaginary even though it still exists and functions, despite being forgotten and buried in the depths of the city? This is the case of very few pictures capable of telling the story of a city, Milan, and its only "real" river, the Olona, whose waters, humiliated and rejected, continue to flow in total amnesia. It is a different story when photography does not have the role of nourishing nostalgia, but the power to make visible and explain the variation of a presence and its progressive obliteration. Some pictures testify to the passage from the bucolic amenity of the river and its banks in a pre-urban context to a muscular urban infrastructure. A rigid channelized river, shown with confidence, is trying to keep its presence, until the moment of its inevitable decline and disappearance. It is in these images that the possibility of reconsidering the Olona as a part of the new project for the city lies.
\end{abstract}

Keywords:

Milan, photography, nostalgia, urban landscape

\section{THEN AND NOW, THE ROLE OF PHOTOGRAPHY BETWEEN REGRET AND NOSTALGIA}

One of the most evident potentialities of photography is the capacity to build up an archive of memories ready to be reactivated the moment they are seen again. Thus, the discovery of facts, people and places unknown to us and the possibility of comparing the past and present state of specific landscape or urban conditions becomes immediate. Speaking of urban landscape, one of the most compelling 
phenomena that exploits this fact is evident in the hyper-distribution of photographic books that present a city, comparing its appearance between "then" and "now." It is a pervasive phenomenon which has no boundaries and concerns major cities all over the world.

This subject is trivial, of little cultural interest, because it is linked to a very elementary way of interpreting the value of photography as an indispensable critical tool. At the same time, however, this phenomenon invites us to reflect on the link between the past and the present and to understand the character of the stratification and complexity that characterises specific urban environments, encouraging reflection that will help plan their future. Despite this interest, there is also very significant risk of giving into a sense of pure nostalgia, and this is the most likely feeling experienced by people that spend some time looking at these images.

We thus unwittingly find ourselves in Maurilia, the imaginary city described by Italo Calvino (1974, p. 30) in which "the traveller is invited to visit the city and, at the same time, to examine some old post-cards that show it as it used to be [...] If the traveller does not wish to disappoint the inhabitants, he must praise the post-card city and prefer it to the present one, though he must be careful to contain his regret at the changes within definite limits: admitting that the magnificence and prosperity of the metropolis Maurilia, when compared to the old, provincial Maurilia, cannot compensate for a certain lost grace, which, however, can be appreciated only now in the old post-cards, whereas before, when that Maurilia was before one's eyes, one saw absolutely nothing graceful and would see it even less today, if Maurilia had remained unchanged; and in any case the metropolis has the added attraction that, through what it has become, one can look back with nostalgia at what it was". There is no doubt that the right attitude to adopt is hard to establish since it is a choice based on feelings, and it prevalently depends on the level of culture and the capacity for critical pre-vision inherent in each individual. It is, therefore, not difficult to encounter a city like Milan, where the images of the old ring of canals that used to surround the historic centre have been viewed and reviewed for years to the point of considering the hypothesis of their partial reconstruction (Cassone et Biscardini, 2014). Reconstruction but not reopening, as is often confusingly indicated, since water no longer runs along most of the project's route under discussion.

This example of a Venetian dream, aimed at reconstructing a city on the water that has now partly disappeared, is engaging compared to studying the value of images concerning contemporary urban reality for two contrasting reasons. Firstly, it demonstrates the evocative and guiding power that images possess, especially if they are skillfully used for a specific purpose, made available and artfully constructed to communicate their message. In this sense, it is important to emphasise that there is complete photographic documentation of the disappeared Milanese canals, an authorial collection commissioned to document the situation before and during the covering works (Cordani, 2004). 
Contrastingly, this availability, richness, and quality of photographic documentation of the Navigli Ring, as well as the relevant literature, is not present in the same way for the other Milanese waters, such as the Olona River, which remains the forgotten protagonist of some faded images, despite the fact that its waters are still present, merely underground, as a neglected, challenged and rejected element of the landscape.

\section{MILAN AND THE RIVER OLONA}

The Olona River originates from springs and hills in the Brinzio and Ganna valleys in the Varese Pre-Alps. After an initial section consisting of the main course and a secondary course, the riverbed becomes a single river near Varese and flows through a densely populated and urbanised area as far as Rho. In this section, the Olona is strongly channelled into an artificial riverbed, characterised by frequent hydraulic works, and fully involved in the urban metabolism of the towns it crosses. In the south of the city of Rho, the river enters the large Milanese conurbation. The main stretch crosses the city underground, while the part of its flow is diverted, especially in flood periods, by two more recent canals: the Olona diverter and the North-West Diversion Canal. This particularly articulated situation also includes a culverted part of the ancient river course that flowed into the Darsena of Porta Ticinese.

This hydraulic situation reflects a very complex history that originated in Roman times, when, given its proximity to the historical centre of Milan, the Olona was, in fact, the subject of profound transformations.

Since the late Imperial Age, the river has been characterised by a complex hydraulic articulation between the natural riverbed and some artificial channels capable of diverting its waters into a network of artificial canals to serve the Roman Mediolanum. Those early transformations produced such a vital variation that it became somehow permanent for several urban hydraulic renewal operations. This closeness to and involvement in the urban dynamics are also the reason why we can speak of the Olona as a "unique" Milanese river.

Thus, since the remote past, the Olona has found its artificial conclusion within Milan, losing the southern part of its ancient natural course and dispersing its waters in numerous outlets. This situation is so complex that even reconstructing the course of the ancient riverbed remains a matter of hypothesis (Poggi, 1913).

Several centuries-old events, the advent of industrialisation and the phase of urban expansion that Milan and the entire Olona Valley underwent since the end of the $19^{\text {th }}$ century onwards have led to an acceleration of the transformations and a substantial change in the river context. It is possible to point out four major changes, all concurrent and correlated. The first was the river course's 
artificialisation and modification, which led to a narrow riverbed constrained within rigid banks and marked by several culverts, crossbars and hydraulic works. The second was the massive urbanisation that accompanied this process. The third was an increase in hydraulic risk due to the massive anthropisation of the river valley - finally, the fourth, a deterioration in water quality related to numerous urban and industrial drains.

These four processes have influenced the planning approach to water management and the continuous modification of the Olona, leading to a progressive adaptation and transformation responding to an increasingly evident degradation. Thus, especially in the most anthropic part, corresponding to the metropolitan section, the solution has been to erase the watercourse presence, leading up to a lack of awareness of its existence that characterises the present (De Marchi, 1948; Columbo, 1960).

Anyone wishing to search for the waters of the Olona in Milan today would have to work hard. Its main course plunges into the city's bowels even before it has crossed the city boundaries between the municipalities of Settimo Milanese and Pero. From here, it will no longer re-emerge as the Olona River, but its waters will only become visible again when they flow into the Lambro Meridionale River, after having travelled about ten kilometres through an entirely underground section. This extensive route is even more significant when considering the oldest ramification, which turned to the Darsena di Porta Ticinese, deprived of water for decades but still existing, also wholly buried. The underground section shows its presence through the upstream outlet in the northern part of the Milanese harbour basin.

\section{PHOTOGRAPHIC FRAGMENTS OF THE OLONA LANDSCAPE}

At this point, it becomes interesting to return to the theme of photography, the relationship it establishes with places, and the profound significance of images concerning urban landscape. In contrast to the considerable number of pictures presenting the disappeared ring of canals, the best-known photographs of the Olona are very few and demonstrate a succession of frenetic transformations that took place in the first six decades of the last century.

The oldest images date back to the first decades of the twentieth century when Milan underwent the first significant phase of urban growth to realise the forecasts contained in Cesare Beruto's urban development plan. The photographs describe the landscape crossed by the Olona, i.e. the La Maddalena neighbourhood, during the flooding events of 1917 (Fig. 1). The pictures, disseminated as post-cards, even more significantly than the maps of the period, allow us to grasp its still suburban dimension, typical of the Milanese countryside, with an evident relationship between the spaces and the river's course. 


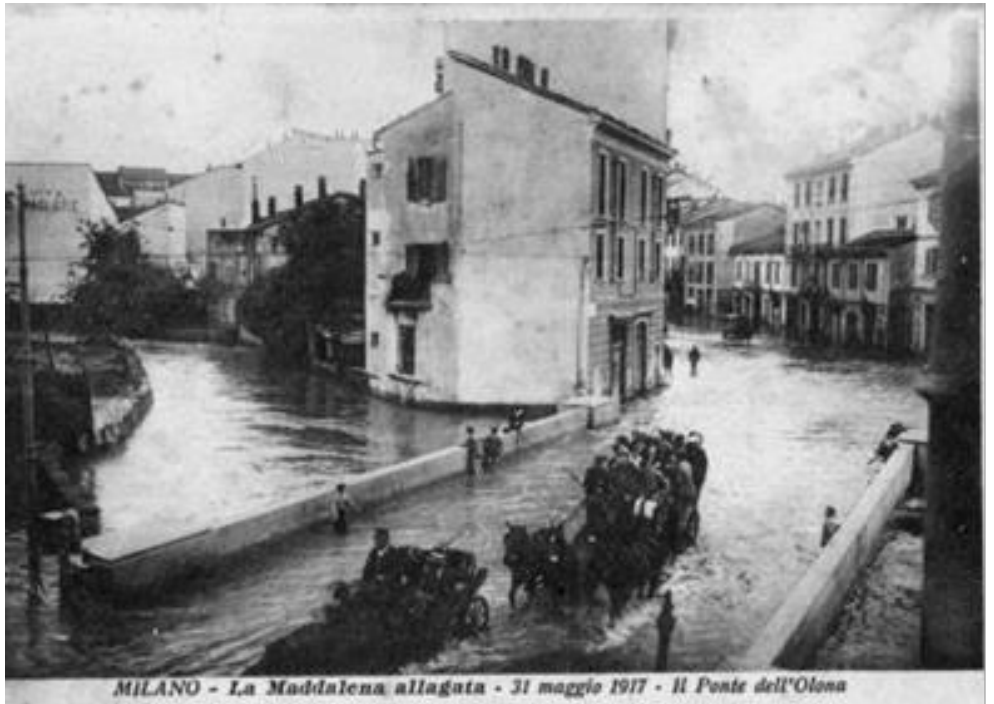

Fig. 1. The landscape of Milan with the Olona River, La Maddalena during the 1917 flood. Source: author's archive.

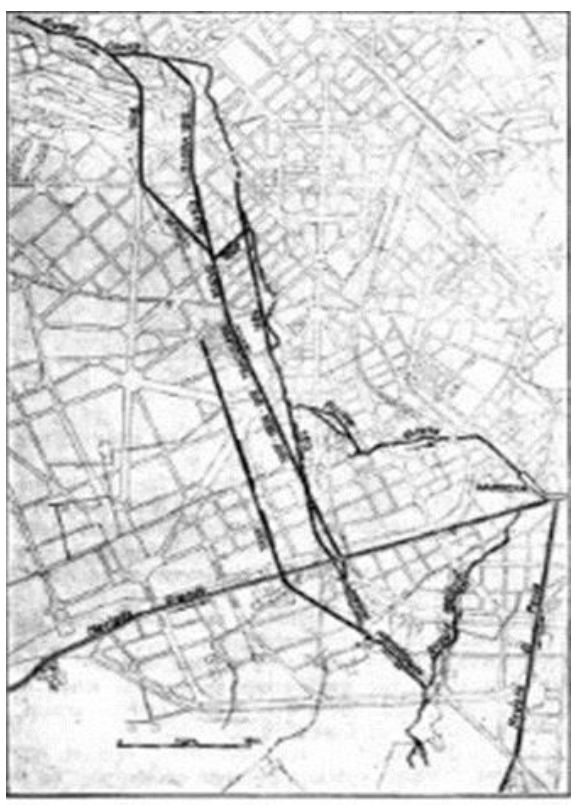

rie. 1. - Trasolati set le deviasione d'Otens

Fig. 2. The Map of Milan: a project to completely transform the river and build a new riverbed for the Olona. Source: author's archive.
These photographs contributed to fixing the depicted identity, even if only partially, while the area was undergoing a substantial transformation. Soon after, the city's growth led to the realisation of a project to completely remodel its course and build a new riverbed for the Olona, changing the river morphology and the relationship with the surrounding spaces (Fig. 2). This important modification was already planned in 1889, and then subsequently incorporated into the great avenues that characterised the urban design envisaged by the 1912 master plan developed by Angelo Pavia and Giovanni Masera to be realised during the fascist regime (Massari, 1929).

A long quiet period in relation to the Olona's fate accompanied the city's growth until the 1930s when some professional photos celebrated the completion of the new Olona riverbed. The shots highlight the transition from the semi-rural 
to urban dimension, with a correspondence between its morphological design and re-articulation of the hydraulic presence (Fig. 3). In the midst of the regime's rhetoric, a desire emerged to give dignity to the presence of the river and enshrine its essence through artificial syntax (Della Morte and Lissoni, 1935).

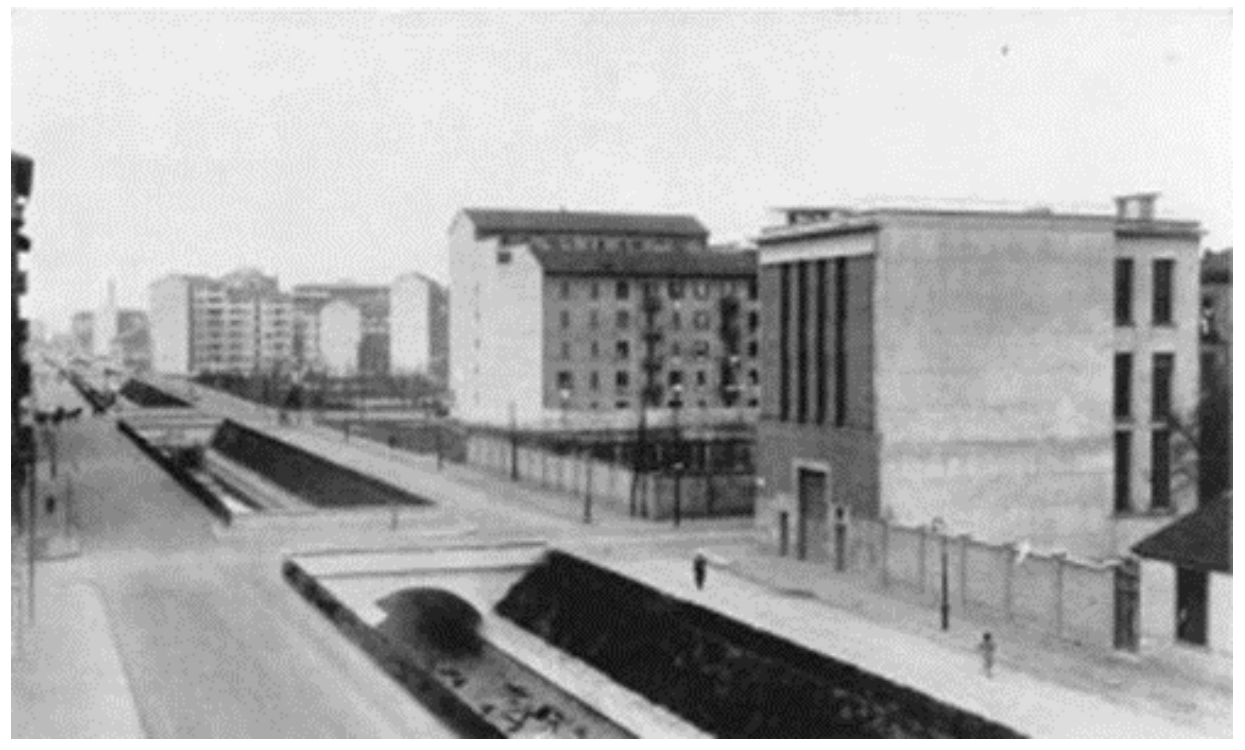

Fig. 3. The first phase of the reconstruction of the Olona riverbed until its filling, 1930s. Source: author's archive.

Few images, however, accompany the brief story of that arrangement. By the end of the 1950s, increasing water pollution levels from civil and industrial sources gave rise to more frequent complaints of stench, which, combined with extensive flooding and the resulting health risks, led to the complete covering of the city's river section (De Marchi, 1948). Several pictures documented this process (Fig. 4, 5). It is almost the last act in the photographic history of Milan's Olona, which from that moment on hid under the ground and fell into oblivion.

The unique exception to this long lack of photographic images of the Olona can be seen in some recent shots available on social media, demonstrating how photography can activate a sort of "hunt for memory," an activity that goes beyond the limits of cartographic reconstruction, and where possible, animates specific explorations of the urban underground world.

These exploratory actions by some fearless investigators of the deep layers of the city are the most recent partial evidence of an occluded reality, testifying to the widespread attention to the topic of underground rivers (Talling, 2011; Bolton, 2011). 


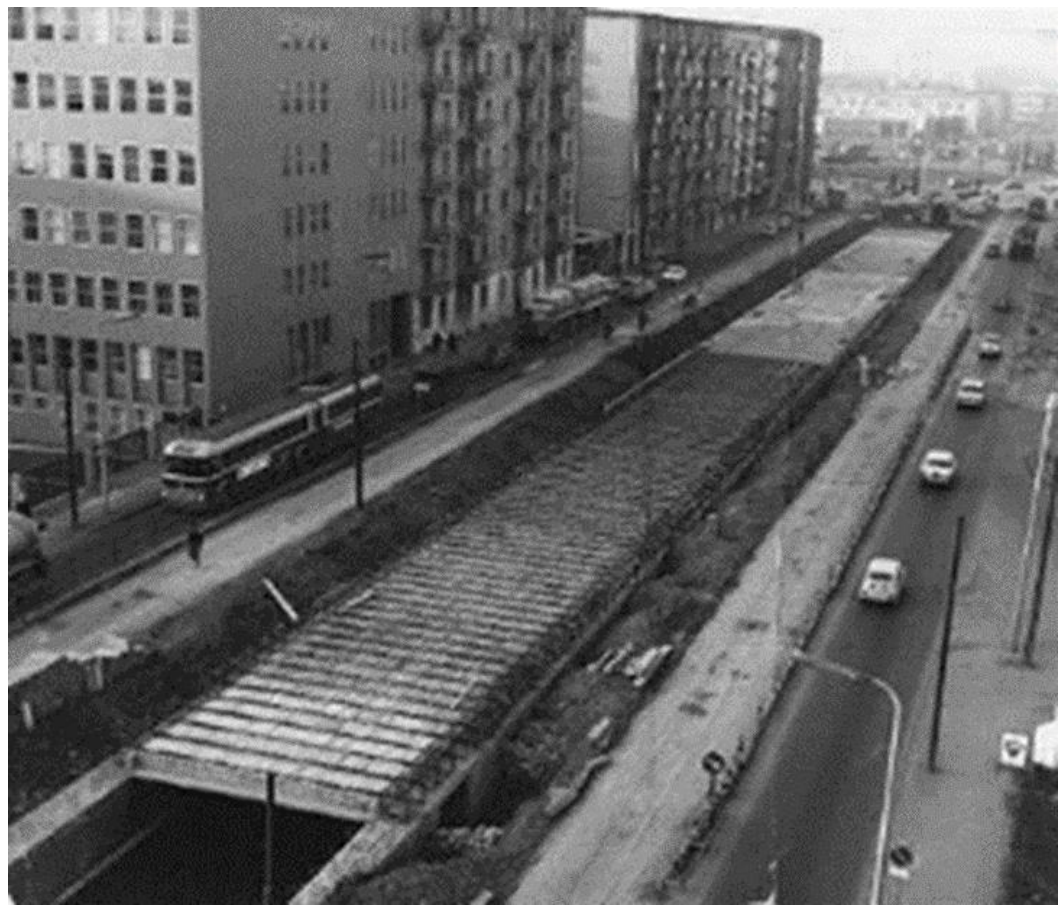

Fig. 4. The second phase of the reconstruction of the Olona riverbed, 1940-50s. Source: author's archive.

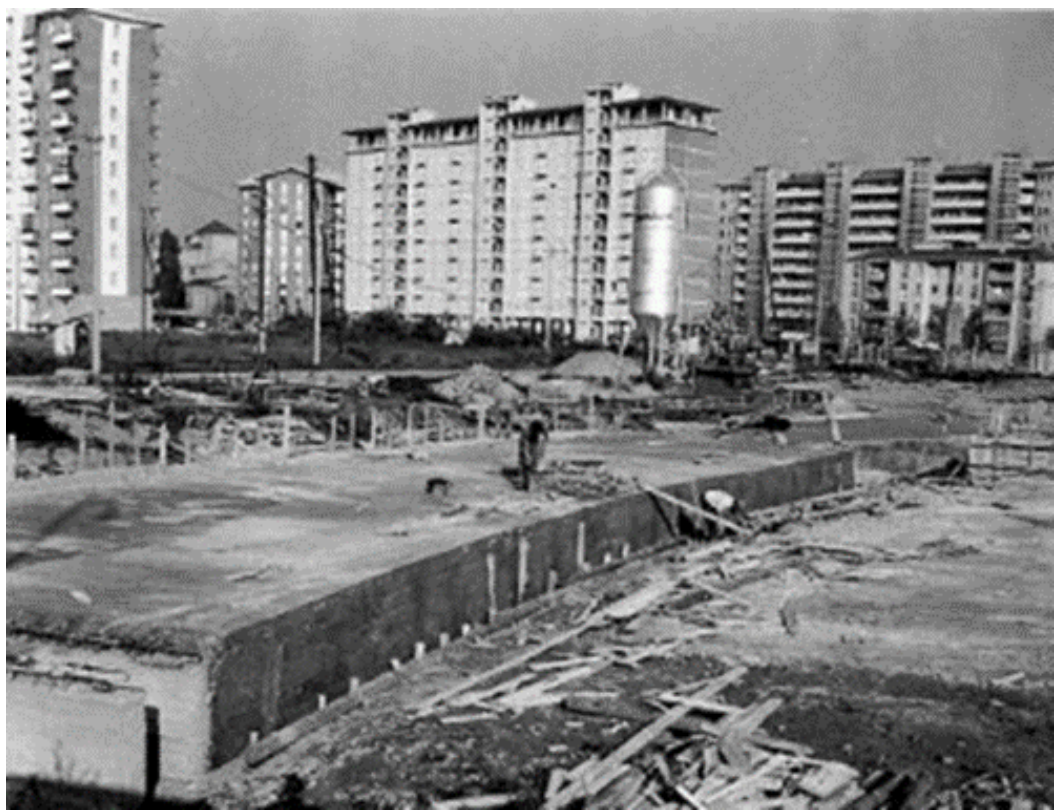

Fig. 5. The third phase of the reconstruction of the Olona riverbed until its filling, 1940-50s. Source: author's archive. 


\section{MUCH MORE THAN NOSTALGIA: PHOTOGRAPHY AS A FIELD OF POSSIBILITY}

The extraordinary evocative power of the photographs of the internal Navigli Ring and their popularity is not even remotely comparable to that of the few images accompanying the alternating history of the Olona. Nevertheless, there is a profound difference between the two: the images of the inner ring of canals refer to an artificial system that remains as a trace and memory, the latter to a natural, deeply anthropogenic river that is still present, but hidden, and whose presence is witnessed precisely because of those images that reconstruct its vicissitudes.

Both series of images echo the feelings that Barthes (1981, p. 82) describes when he explains that "The Photograph does not call up the past (nothing Proustian in a photograph). The effect it produces upon me is not to restore what has been abolished (by time, by distance) but to attest that what I see has indeed existed. At the same time, however, the photos of the Olona refer to a changed but still existing reality. For the Navigli, the consequence of photography is to nourish nostalgia, encourage the 'Venetian' dream, and allow us to recognise that 'Photography has something to do with resurrection"' (Ibidem). For the Olona, photography depicts a surgical ritual that unveils the layers of matter and then recomposes them, revealing the palimpsest (Corboz, 1983; Carandini, 2017). In the case of the Olona, it is exceptionally true that "even if we know that we cannot change the past depicted in the photograph, the wish offered by the photograph's not-yet future makes the retrospection valuable. We must start looking for future possibilities offered by photographs, thereby allowing one to think 'what could be, if.' This approach liberates both photography and history-and eventually us-from their strict connection to facts" (Helmerdig, 2016, p. 21).

For this reason, it can be argued that this forgotten, hidden, and rejected urban portion of the Olona is still part of the Milan heritage, and it can represent a valuable element of its future. This possibility is achievable, also thanks to photography which can establish a "productive tension" capable of putting back in order the "idiosyncrasies of memory" (Sterling, 2019).

The evocative power of the images of the Olona thus translates into the possibility of recognising its presence, a fact which, in the midst of the Anthropocene and the challenges of climate change (Serres, 1991; Tsing et al., 2017; Latour, 2020), invites us to consider its presence differently. This consideration opens up a perspective that is perhaps utopian or, more likely, dramatically realistic. Considering water as an increasingly complex resource will perhaps one day make it possible to photograph the Olona again in relation to its city: Milan. It will be a different river, just as the passages accompanying its centuries-old history are different. 
This perspective is certainly not unfounded. On the one hand, it reflects an ongoing process in which the world's major cities are re-discovering, in a literary sense, rivers and streams buried under the city's surface. A clear example of this is a growing number of associations operating in the vast field of river restoration, with several organisations dealing with the specific topic of "deculverting" or daylighting. These are bodies that promote operations that are only mistakenly considered "impossible," convinced that this action could positively impact local communities, including potential social, economic and environmental benefits (Wild et al., 2010). Numerous case studies worldwide exemplify the possibility of recovering the visual presence of forgotten watercourses within a process of urban reform, capable of reintroducing water into the genetic code of the city as a vital element, participating in the form of articulated plurality (Ranzato, 2017). The most obvious obstacle to the implementation of such plans, apart from the cost, is the critical condition of the water. We are aware, however, of continuous minor signs of improvement, which could give hope for a real possibility of redemption. The hybrid and plural nature of the infrastructure (Alonzo, 2016) does the rest, offering the foundations to build architecture capable of restoring the form and visibility to the water.

On the other hand, another factor that should not be overlooked is infrastructure maintenance in relation to climate change. There is no lack of studies in the literature warning of the greater need for care that infrastructure will require over the next few decades due to the increased stress levels it will be subjected to (Neumann et al., 2013). Thinking about vast covered stretches makes one realise the difficulties of inspection, the criticality of maintenance, and the fragility of certain structural parts, including the horizontal slab. If we consider the medium age of many infrastructure elements and the risk of failure acceleration, it is easy to understand how massive interventions may be necessary but not always sustainable. This consideration is evident not onlywith regard to economic reasons but also in confrontation with the benefits of a possible reopening. In addition, it should be considered how the topic of climate change opens up an enormous possibility of reflection on the range of options that the presence of a watercourse can bring within a process of an overall rethinking of urban water management methods.

In the Milanese panorama, the photographs of the Olona tell us of its evolution and bear witness to its presence. There is no such thing as nostalgia because one cannot be nostalgic for something that was once a problem for the city in terms of safety, pollution, and limits on development. However, these photos show how this infrastructural reality has been incessantly modified, 
making it clear that there is a very high likelihood of further change, as the process of transformation continues. Thus, those photographs are offered not as icons of reality to be re-proposed but as witnesses of a presence whose essence is somehow preserved and can be brought back into play.
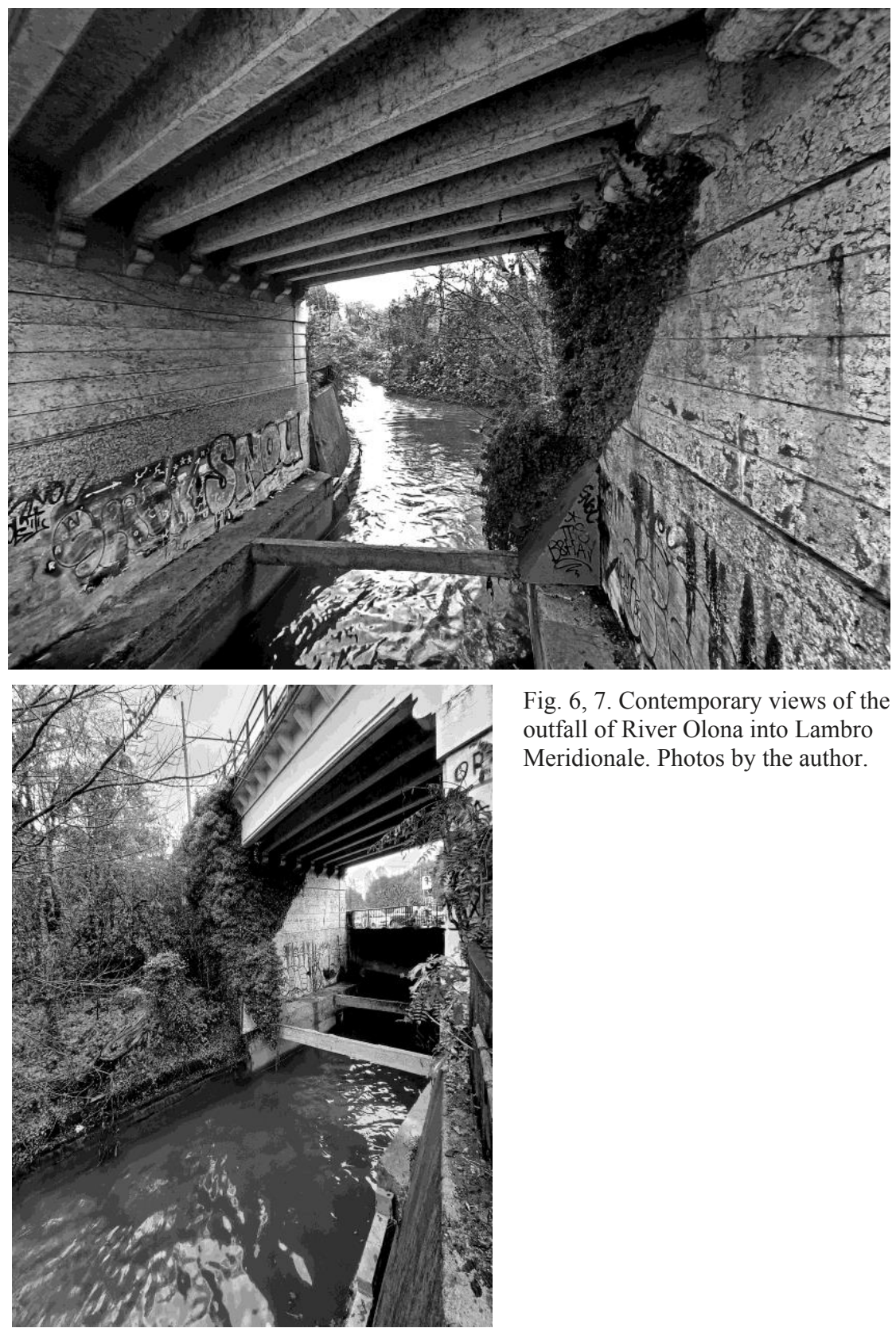

Fig. 6, 7. Contemporary views of the outfall of River Olona into Lambro Meridionale. Photos by the author. 


\section{BIBLIOGRAPHY}

Alonzo, È. (2016). Les apories de l'hybride. Pour une nouvelle relation entre architecture et infrastructure. Marnes documents d'architecture, 4, pp. 290-307.

Barthes, R. (1981). Camera Lucida. New York: Hill and Wang.

Bolton, T. (2011), London's Lost Rivers: a walker's Guide. London: Strange Attractor Press.

Calvino, I. (1974). Invisible cities. San Diego: Harcourt Brace Jovanovich.

Carandini, A. (2017). La forza del contesto. Bari-Roma: G. Laterza \& Figli.

Cassone, A. and Biscardini, R. (2014). Riaprire i navigli si può. Un grande progetto per Milano. Milano: Biblion.

Columbo, A. (1960). La Fognatura di Milano. Storia, indagini, studi, progetti. Milano: Quaderni della Città di Milano.

Corboz, A. (1983). The Land as Palimpsest. Diogenes, 31 (121), pp. 12-34.

Cordani, R. (2004). Milano, il volto di una città perduta. Milano: CELIP.

De Marchi, G. (ed.), (1948). Sistemazione delle acque della zona lombarda fra Ticino e Adda. Milano: Macciachini.

Della Morte, S. and Lissoni, O. (1935). La Milano voluta dal Duce e la vecchia Milano. Milano: Officine Grafiche Esperia.

Gambi, L. and Gozzoli, M. C. (1982). Le città nella storia d'Italia: Milano. Bari-Roma: G. Laterza \& Figli.

Helmerdig, S. (2016). Fragments, Futures, Absence and the past. A new approach to photography. Bielefeld: Transcript.

Latour, B. (2020). La sfida di Gaia. Il nuovo regime climatico. Roma: Meltemi.

Marescotti, C. (1956). La sistemazione idraulica del territorio milanese. Atti del Collegio degli Ingegneri di Milano, 7-8, pp. 1-8.

Massari, U. (1929). La deviazione del fiume Olona secondo il tracciato di Piano regolatore (legge 12/7/1912, n. 866) e la sistemazione del fiume Lambro Meridionale. Milano: Stabilimento Tip. Stucchi.

Neumann, J. E. et al. (2015). Climate change risks to U.S. infrastructure impacts on roads, bridges, coastal development, and urban drainage. Climatic Change 131, pp. 97-109.

Poggi, F. (1913). Le Fognature di Milano. Milano: Vallardi.

Ranzato, M. (ed.) (2017). Water Vs. Urban Scape. Exploring Integrated Water-Urban Arrangements. Berlin: Jovis.

Serres, M. (1991). Il contratto naturale. Milano: Feltrinelli.

Sterling, C. (2019). Heritage, Photography, and the Affective Past. London: Routledge.

Talling, P. (2011). London's Lost Rivers. London: Random House Books.

Tsing, A. et al. (eds.), (2017). Arts of living on a damaged planet. Minneapolis: University of Minnesota Press.

Wild, T. C., et al. (2011). Deculverting: reviewing the evidence on the "daylighting" and restoration of culverted rivers. Water and Environment Journal, 25, pp. 412-421. 